\title{
LEAN CONSTRUCTION AND ORGANIZATIONAL KNOWLEDGE CREATION
}

\author{
Bianca T. Trentin ${ }^{1}$ and Bernardo M. B. S. Etges ${ }^{2}$
}

\begin{abstract}
It is essential for the construction industry to continuously create new knowledge, aiming at innovation and maintaining competitiveness. As for Lean Construction in addition to improving construction processes, the characteristic inherent in its implementation is that of creating collaborative, interdisciplinary moments with a high level of information sharing, which shows the great potential of the methodology for the creation of knowledge. This article sets out to analyze how people participating in Lean Construction implementation projects see the potential of Lean Construction for creating knowledge. To do so, in addition to a thorough review of the literature on the subject, the results of a form-based survey conducted with six Brazilian construction companies, partners of a consultancy company, are presented. The results show that everyone surveyed agrees that Lean Construction increases the sharing of information between people, the creation of improvement actions for projects, and finally, knowledge creation for the company. This perception is sharper in people who occupy management positions than in those in operational positions. Also, the present study concludes that the most effective way to generate organizational knowledge in Lean Construction implementation projects is to combine tools, methods and training that make use of both tacit and explicit knowledge.
\end{abstract}

\section{KEYWORDS}

Lean construction, tacit knowledge, explicit knowledge, learning, knowledge creation.

\section{INTRODUCTION}

It is widely recognized that in order to remain competitive in the market and grow sustainably, companies need to constantly create new knowledge, and thus to accompany the rapid changes in technology, markets and society today. However, there is still little understanding of how organizations create, maintain and exploit knowledge dynamically (Nonaka, Toyama and Konno 2000).

The construction industry is positioned as one of the branches of industry which has least advanced in technology and productivity gains, and knowledge is one of the essential assets for companies that strive to position themselves competitively with regard to innovation and value creation (Nonaka et al. 2014; Zhang and Chen 2016). One of the factors that contribute to this advance in promoting knowledge is the procedural view of

$1 \quad$ M.Sc. Eng. Student, Lean Construction Consultant, Climb Consulting Group, University of Rio dos Sinos, Porto Alegre, Brazil, bianca8tt@ gmai.com, orcid.org/0000-0001-6023-0439

2 PhD Candidate, M.Sc. Eng., Founding-Partner at Climb Consulting Group, Federal University of Rio Grande do Sul, Porto Alegre, Brazil, bernardo.m.etges@gmail.com, orcid.org/0000-0002-3037-5597 
production activities. Thus, implementing lean construction depends largely on organizational learning and knowledge creation. According to Zhang and Chen (2016), applying Lean can even improve the factors related to this organizational learning.

What this means is that Lean Construction is not just about learning to use tools and applying them. In reality, its essence is to create a collaborative environment between those involved in the enterprise, thereby creating moments of discussion and interaction, generating solutions, learning and creating opportunities for innovation. And what would all that be about, if not a way to create, maintain and explore knowledge dynamically? (Christensen and Christensen 2010; Skinnarland and Yndesdal 2012)

This article sets out to analyze the understanding of knowledge creation during the implementation phases of Lean Construction. Such analysis is performed based on the understanding of team members who were members of teams that implemented the methodology and tools of Lean Construction.

There is already a rich bibliography for this field of study which has been developed by academics and researchers with extensive experience in the subject and is presented in the review of the literature. However, the theme of Lean Construction is still incipient in Brazil, being mainly concentrated in consultancies and large companies. The perception of construction professionals about the results of implementing Lean Construction in Brazilian projects has hitherto been little explored in Brazil. Seeking to fill this gap, the authors conducted a survey of 6 Brazilian companies, which were undergoing stages of implementing Lean Construction and Operational Excellence in partnership with a Consulting company. The aim of the research with these six cases was to identify the participants' perception of the knowledge generated in the projects, by exploring in-depth the distinction between explicit and tacit knowledge during the implementation of Lean Construction. Moreover, these perceptions were discretized by the function and hierarchical level occupied by the respondents of the survey (operational and leadership level). From this, the main findings, the limitations of the study and issues for future research are presented.

\section{REVIEW OF THE LITERATURE}

\section{LEARNING AND KNOWLEDGE}

An organization that learns is like a process that evolves over time. In other words, it is an organization with the skills to create, acquire and transfer knowledge (Garvin 2000). Organizational learning requires individual and collective learning (Moland 2007), and it is only when people learn together effectively that organizations can change (Senge and Scharmer 2006).

The knowledge existing within an organization can be exploited when dealing with problems, thus deepening, defining and developing its own solutions (Tyagi et al. 2014). During this problem-solving exercise, teams not only take actions to find solutions, but also acquire dynamic knowledge on an ongoing basis. Organizations cannot be treated as machines that process information, but as entities that create knowledge through action and people interaction (Nonaka, Toyama and Konno 2000).

Nonaka (1994) offers a dynamic learning theory that shows a connection between the concepts of teamwork, creativity and innovation. He explains how knowledge can become available to other people by means of collaborative activities. In addition, he explains how teamwork and creativity help to test and develop knowledge (Nonaka 1994). 
His theory shows how learning occurs in collaboration with other people, especially when the knowledge and experience that they have are different.

\section{TACIT KNOWLEDGE AND EXPLICIT KNOWLEDGE}

Knowledge is divided into two categories: explicit knowledge and tacit knowledge (Nonaka et al. 2014). Explicit knowledge is encoded and stored in formal language and shared in the form of data, figures, specifications, manuals, etc. so that it can be easily transferred between individuals in the organization. On the other hand, tacit knowledge is difficult to transmit and encode. It is subjective and deeply rooted in an individual's actions, attitudes, commitments, ideals, values and emotions (Zhang and Chen 2016)

The effective transfer of tacit knowledge requires personal contact, regular interaction and trust by means of sharing experiences and imitation. Many researchers consider tacit knowledge to be a source of competitive advantage and consider it more conducive to organizational innovation. This is mainly because tacit knowledge is developed based on a company's human resources in relation to the intellect, skills and experience of its employees, which are difficult to imitate, difficult to replace and can create value. However, tacit knowledge will quickly lose its meaning without the basis and support of explicit knowledge (Nonaka, Toyama and Konno 2015; Tyagi et al. 2015; Zhang and Chen, 2016).

An organization creates knowledge by exploiting the interactions between explicit knowledge and tacit knowledge. Their interaction is called 'knowledge conversion' (Nonaka et al. 2014). By using the conversion process, tacit and explicit knowledge expands in quality and quantity. This is a dynamic, continuous and self-transcending process (Nonaka, Toyama and Konno 2015; Zhang and Chen 2016). A four-stage spiral model abbreviated as SECI (Socialization, Externalization, Combination and Internalization) modes was built to represent this conversion process (Nonaka 1994; Nonaka and Takeuchi 1995).

\section{Lean Construction AND THE CReation OF KNOWLEDGe}

Lean construction aims to manage and improve construction processes at minimum cost and maximum value while considering the needs of the customer (Zhang and Chen 2016). To make the link between the knowledge creation process and Lean Construction, we draw attention to results from important and relevant studies on the topic.

The study by Zhang and Chen (2016) analyzes the tools and techniques of lean construction individually, in a quantitative way, thereby creating relationships with their effectiveness at creating knowledge. This helps to understand why tools have an important role in the construction industry. Their study finds a consequence relationship between (a) applying tools; (b) creating efficient knowledge; (c) increasing innovation in construction companies; (d) eliminating waste; and (e) maintaining competitiveness. (Zhang and Chen 2016)

The paper by Tyagi et al. (2015) also incorporates an analysis of the context of knowledge creation. Their work presents a set of ten lean construction tools and methods that have been proven to assist in the process of knowledge creation, generating context so that dynamic knowledge and innovation may take place in companies. The authors evaluate the set of lean constructions tools by using a model that involves the interplay between tacit and explicit knowledge in a "ba" context to generate knowledge during the four SECI modes and to update the knowledge assets. According to the authors, a great gain from implementing methods and tools is that expensive rework is reduced at sites 
because since knowledge has been created at the right time and in the right place, future projects start from a higher level of excellence, in which the culture developed sees to it that the right decisions are taken faster and the quality of the products and processes is improved (Tyagi et al. 2015).

Christensen and Christensen (2010) examine the hypothesis that Lean Construction is a tool for interdisciplinary learning and can be used to benefit organizations, not just projects. By interpreting a theoretical framework and carrying out a case study, they validate the hypothesis and conclude that cooperation between different professions and the sharing of plans lead to the sharing of learning and understanding of the construction processes of the project as a whole (Christensen and Christensen 2010).

Pasquire and Court (2013) present a model in which they propose that the formation of knowledge is a productive process within construction projects. The generation of common sense about knowledge represents a significant step towards eliminating waste in the design and delivery of construction projects (Pasquire and Court 2013).

Nevertheless, Skinnarland and Yndesdal (2012) validated the hypothesis that the Last Planner® System ${ }^{3}$ can contribute to the process of creating knowledge in construction projects. However, they emphasize that there are premises for the success of the process, such as leadership skills and management of the leaders involved. It is imperative to establish an atmosphere within the project that builds trust, collaboration and a safe environment in terms of reporting errors and delays to people in the group. The Last Planner® System fulfills this integrating function and requires the team involved to be willing to change, based on joint reflection, by communicating and sharing new knowledge, in addition to the team's acting on explicit knowledge obtained (Skinnarland and Yndesdal 2012).

\section{METHODOLOGY}

This article was built from a qualitative survey by applying a questionnaire designed to understand the perception of the sample of participants in Lean implementation projects in Brazil about how Lean Construction contributes to creating knowledge.

The survey was applied to clients of a Brazilian Consulting Company, in which the authors of the article are members. The survey was applied to a sample of 29 respondents, from 6 different companies ( 2 developers and construction companies of residential buildings, 2 construction companies in the renewable energy sector, 1 construction company for industrial and commercial works and 1 energy generation and transmission company) who were actively participating in Lean Construction implementation projects that were being undertaken in partnership with the Consultancy Company. The six projects went through stages of implementing the Last Planner ${ }^{\circledR}$ System cycle, approaches to improving operations by using Kaizen and formal training. The 29 respondents were selected based on their involvement in the projects and on the positions they occupied in the companies. The research sought to have a complete and heterogeneous sample within each project.

The limited number of projects and respondents in the sample analyzed may be regarded as a limitation of the study. However, the aim of the sample is to guide understanding about knowledge creation as a result of implementing Lean Construction in the process of generating value for organizations. Moreover, from the answers obtained,

\footnotetext{
3 "Planning methodology broadcast when implementing Lean Construction" (Ballard and Howell 1997)
} 
graphic analyses and cross-analyses of the perceptions versus profile of the respondents could be generated, which underpinned the discussion on the topic.

The 8 questions of the survey were aimed at creating an understanding of the respondents' perception of collaboration issues, problem solving and knowledge creation in the Lean Construction projects in which they have participated. The survey can be accessed through the link: https://forms.gle/Ka4rTUbiAnvUPxVG66.

From the literature review and because of the collaborative approach promoted by the Consultancy Company in the Projects under analysis, the authors assumed that the application of Lean Construction Tools would generate an environment for sharing tacit knowledge, due to its moments of collaboration and practice, and due to the moments of acquiring skills and training and, above all, they would share explicit knowledge, for making use of data, methods and formal language. Thus, the survey sought to identify in the end what the respondents perceived as to what added the greatest value for creating knowledge for people, the project and the organization: explicit knowledge, tacit knowledge, or a combination of the two.

\section{RESULTS}

In all six companies that participated in the survey, both the practical application of Lean Construction tools, as well as formal skills training and general training on Lean Construction and Operational Excellence had taken place. In addition, in all six companies, these moments involved the participation and collaboration of people at the operational and management levels. Table 1 shows the Implementation phases included in each of the companies and the length of the time of involvement and knowledge transfer between the Consultants and the Team from the companies.

Table 1: LC tools implemented in the companies analyzed

\begin{tabular}{|c|c|c|c|c|c|c|c|c|}
\hline & \multirow{2}{*}{$\begin{array}{c}\text { LC } \\
\text { Implementa } \\
\text { tion time }\end{array}$} & \multicolumn{5}{|c|}{ Application of Lean Construction Tools } & \multicolumn{2}{|c|}{ Formal Skills Training } \\
\hline & & $\begin{array}{c}\text { Line Of } \\
\text { Balance } \\
\text { (LOB) }\end{array}$ & Kaizen & $\begin{array}{l}\text { MF } \\
\text { V }\end{array}$ & $\begin{array}{l}\text { Look } \\
\text { Ahead }\end{array}$ & $\begin{array}{l}\text { Check- } \\
\text { in/Check- } \\
\text { out }\end{array}$ & $\begin{array}{c}\text { Training } \\
\text { Operation } \\
\text { al } \\
\text { Excellence }\end{array}$ & $\begin{array}{l}\text { Training in } \\
\text { LC concepts }\end{array}$ \\
\hline $\begin{array}{c}\text { Company } \\
1\end{array}$ & 8 months & $x$ & $x$ & $x$ & $x$ & $x$ & $x$ & $x$ \\
\hline $\begin{array}{c}\text { Company } \\
2\end{array}$ & 7 months & $x$ & $x$ & $x$ & $x$ & $x$ & $x$ & $x$ \\
\hline $\begin{array}{c}\text { Company } \\
3\end{array}$ & 3 months & & $x$ & $x$ & $x$ & $x$ & $x$ & $x$ \\
\hline $\begin{array}{c}\text { Company } \\
4\end{array}$ & 2 months & $x$ & & & $x$ & $x$ & & $x$ \\
\hline $\begin{array}{c}\text { Company } \\
5\end{array}$ & 20 months & & & & $x$ & $x$ & $x$ & $x$ \\
\hline $\begin{array}{c}\text { Company } \\
6\end{array}$ & 5 months & $x$ & & $x$ & $x$ & $x$ & $x$ & $x$ \\
\hline
\end{tabular}

It is pointed out that of the respondents, $25 \%$ hold management positions (Coordinator, Manager and Director) and $75 \%$ hold operational positions (Engineer, Analyst, Technician, Intern, Architect, Supervisor / Master of Works, Supervisor).

All 26 respondents of the survey showed that they believe that, at least at some point during the course of the projects in their companies, implementing Lean Construction tools led naturally to (1) sharing information, (2) improvement actions for projects being 
created, and finally, (3) to creating knowledge for the company. According to Nonaka (1994), in order for knowledge to be developed, creative chaos is necessary. This means an abundance of information, the variation of specific pieces of knowledge and collaboration. The results indicate that implementing Lean Construction tools serves as support for the creation of this abundance of information and for creativity.

More specifically, looking only at question (1) information sharing was accentuated positively due to implementing Lean Construction tools, and we can see that there is a greater degree of sharing at the project management level than at the operational level. The results for this question are positive and are shown in Figure 1. At the project management level, $86 \%$ of respondents believe that implementing Lean Construction tools always favors the greatest and best information sharing.

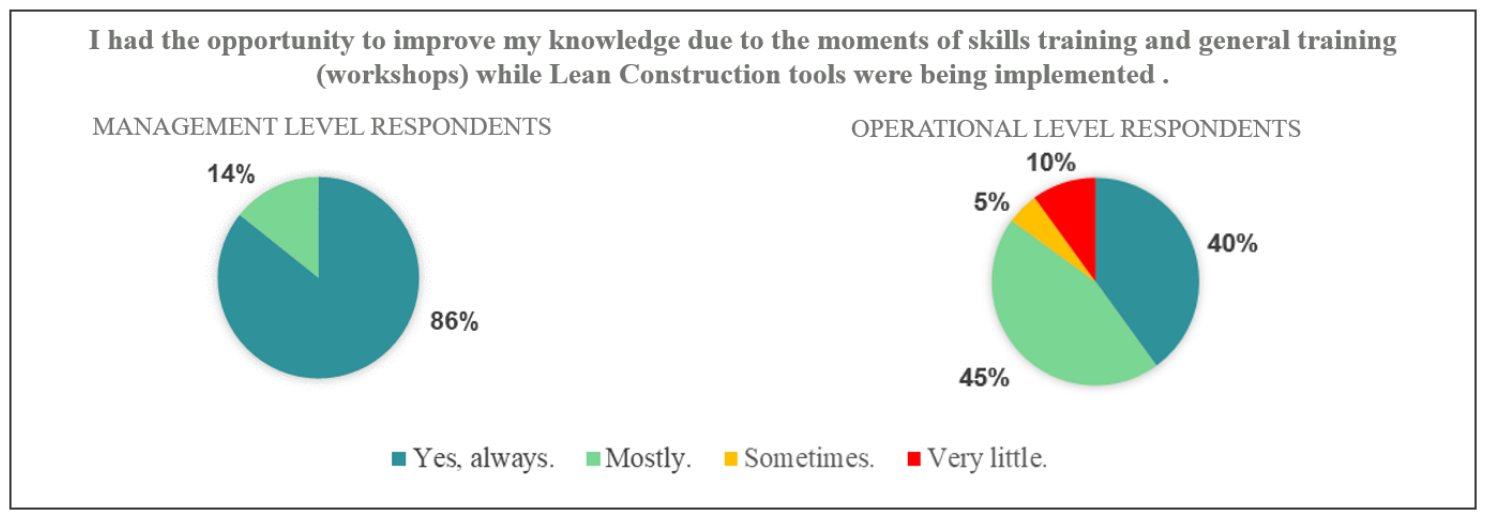

Figure 1: Answers to Question 1 of the survey

Regarding the contribution to (2) creating improvement and problem-solving actions for the project, $84.9 \%$ of the respondents identified that, in most cases of implementing Lean Construction tools, this aspect is favored. Once again, the results at the management level are more favorable than at the operational level, where $86 \%$ of respondents at the management level believe that, whenever the implementation of Lean tools occurred, improvement actions were generated, as opposed to $15 \%$ of respondents at the operational level who gave the same answer. Figure 2 illustrates the distribution with regard to generating improvement and problem-solving actions.

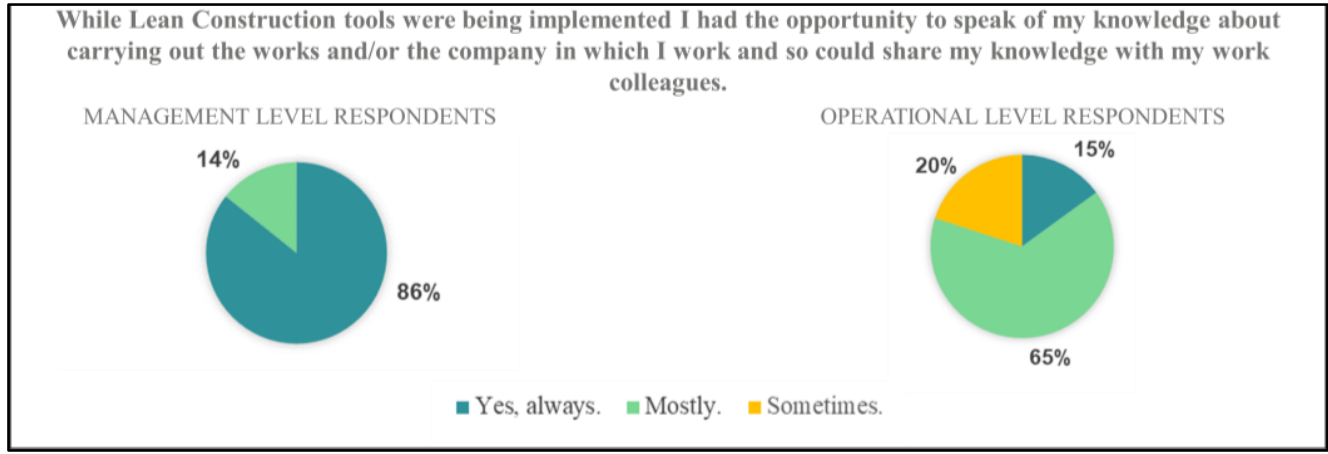

Figure 2: Answers to Question 2 of the survey

After having analyzed the results from (3) creating knowledge for the company, due to the collaboration and proximity created between people when implementing Lean Construction tools, the results found are equally positive, with the constant of being even more positive in the management positions of the project than at the operational level. It 
is highlighted in Figure 3, that, in this regard, even at the operational level, $90 \%$ of respondents believe that, in most implementations, knowledge was generated for the company.

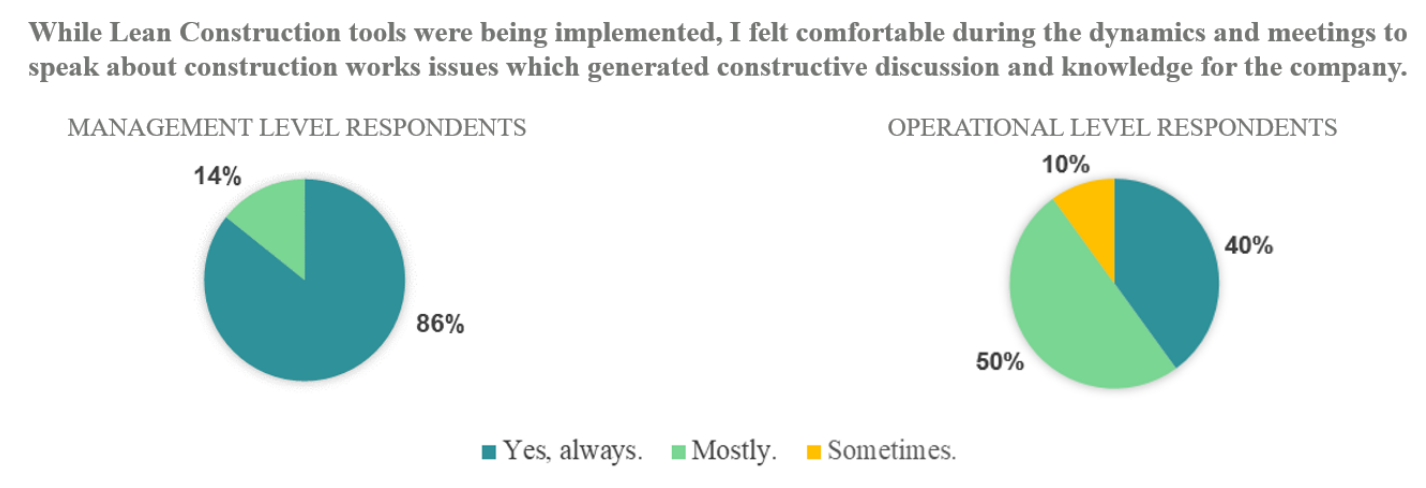

Figure 3: Answers to Question 3 of the survey

Analyzing the results of questions 1,2 and 3, specifically the constant fact that the results are more positive at the management level than at the operational level, raises the question of how secure people at the lowest levels of the organizational hierarchy feel about speaking up at daily meetings, when Lean Construction tools are being applied and in training moments. Even though the results show that Lean allows an environment of dialogue and collaboration, it is still necessary to achieve a greater degree of maturity, with a view to taking action to reduce the defense mechanisms of employees and creating an atmosphere of learning and trust, so that no one is afraid they will be attacked or criticized (Skinnarland and Yndesdal 2014).

Nevertheless, the research sought to understand the respondents' point of view in relation to tacit and explicit knowledge. Although explicit knowledge, generated through formal training, has extremely expressive returns, tacit knowledge emerges as a great aggregator of results in the work environment: $85.2 \%$ of respondents identified that in most cases of formal skills training and general training on Lean Construction, their knowledge was improved, which allows us to infer that in these cases there was transfer and generation of explicit knowledge; and $92.6 \%$ of the respondents identified that in most cases of the practical application of the Lean Construction tools their knowledge was improved, which enables it to be inferred that in these cases there was a transfer and generation of tacit knowledge.

For Nonaka (1994) and Polanyi (1966), organizational learning occurs in the interaction between tacit and explicit knowledge, when the individual's tacit knowledge is made available, tested and transformed into practical use. On the other hand, explicit knowledge is codified and articulated, during which it can be captured, communicated, stored and promptly transmitted to other people. The results of the research in this article support what the aforementioned authors argued. When asked, 81.5\% of respondents considered that the best way to generate knowledge is to combine explicit knowledge (workshops, training) with tacit knowledge (practical application of the tools), and not to use only one of them in isolation.

The fact that the study is based on a qualitative approach that was applied to 6 companies and 29 respondents is emphasized. This is a limitation with regard to validating the theories presented. Moreover, the authors' inferences that the moments of formal training/ workshops generate explicit knowledge and that the application of the 
tools generates tacit knowledge were carried out based on the literature review and on the collaborative character of the ongoing projects, which opens space for new validation studies.

\section{CONCLUSIONS}

This article has met its main objective by providing a broad and thorough discussion about the creation of knowledge in Lean Construction projects. The literature review together with the data collected by applying the questionnaire to the 6 companies that were focused on in this paper underpinned the basis for stating that tacit knowledge and explicit knowledge, on acting together, enable those involved in the Lean Construction Implementation process to perceive more clearly the value of knowledge development.

Christensen and Christensen (2010) Zhang and Chen (2016), Tyagi et al. (2015) and Skinnarland and Yndesdal (2012) have already attested in a similar way that Lean Construction implementation projects have great potential for generating knowledge due to their characteristic of creating interdisciplinary and collaborative learning, as their tools require the cooperation of different professionals, the sharing of plans between sectors and an understanding of construction processes as a whole.

In a complementary way, the present study concludes that the most effective way to generate organizational knowledge in Lean Construction implementation projects is to combine tools, methods and training that involve both tacit knowledge and explicit knowledge since $81.5 \%$ of the answers favor the use of the two methodologies combined. During the implementation of Lean Construction tools, the tools and methodologies provide support for the transformation of tacit knowledge into explicit knowledge in an infinite spiral (Tyagi et al. 2015), and this is perceived by the respondents. $85.2 \%$ of respondents identified that in most cases of skills training and general training on Lean Construction, their knowledge was improved, which enables it to be inferred that, in these cases, explicit knowledge was transferred and generated; and 92.6\% of the respondents identified that in most cases, when Lean Construction tools were applied in practice, their knowledge was improved, which enables it to be inferred that, in these cases, tacit knowledge was transferred as was the generation of tacit knowledge. As mentioned before, although explicit knowledge, generated through formal training, has extremely expressive returns, tacit knowledge emerges as a great aggregator of results in the work environment. This research conclusion is important when analyzed in conjunction with the theory that tacit knowledge will quickly lose its meaning without the basis and support of explicit knowledge (Nonaka, Toyama and Konno 2015; Tyagi et al. 2015; Zhang and Chen, 2016).

One point observed was the variation between people in management and operational functions in the perception of knowledge generation and the formation of a collaborative environment. Therefore, it is suggested that future studies specifically verify if there are knowledge generation biases in each audience.

Although the study presents the limitation of having only 29 respondents for qualitative research, this point raised from the survey has great potential. Efforts should be made to deepen the practical use and understanding of models in order to foster operational teams to have greater confidence and involvement in the knowledge building routines by means of Lean Construction.

Still on future studies, two more points are suggested. The first is based on the fact that the sample analyzed consists entirely of Brazilian companies and participants, so future studies could replicate this research in other countries with different contexts and levels of Lean Construction maturity. The second suggestion concerns the individual 
analysis of each Lean Construction tool applied to the projects, regarding their characteristics of knowledge generation due to the interaction between tacit and explicit knowledge in SECI process, as presented by Tyagi et al. (2015), which analyzes different LC tools with a similar approach.

Finally, it is emphasized that it cannot be concluded from the research that creating efficient knowledge can increase innovation in construction companies, thereby solving issues, eliminating waste and maintaining competitiveness, as mentioned by Zhang and Chen (2016). Thus, it is also suggested that future studies should analyze the question: how does the knowledge generated by implementing Lean Construction promote innovation, competitiveness and the elimination of waste?

\section{ACKNOWLEDGMENTS}

The authors are grateful to Climb Consulting Group and partner companies and clients for their collaboration in this research.

\section{REFERENCES}

Ballard, G., and Howell, G. 1997. "Implementing lean construction: stabilizing work flow." IGLC, 101-110.

Christensen, R. M.; Christensen, T. N. 2010. "Lean construction facilitates learning on all organisational levels? Challenging Lean Construction Thinking: What Do We Think and What Do We Know?" - 18th Annual Conference of the International Group for Lean Construction, IGLC 18, n. July, p. 406-414.

Garvin, D.A. 2000. "Learning in action: A guide to putting the learning organization to work". Harvard Business Press.

Moland, L. (2007). "Flink med folk i norske kommuner." Fafo, Oslo, Norway

Nonaka, I. (1994). "A dynamic theory of organizational knowledge creation." $O$ Organization Science, 14-37

Nonaka, I. et al. 2014. "Dynamic fractal organizations for promoting knowledge-based transformation - A new paradigm for organizational theory". European Management Journal, v. 32, n. 1, p. 137-146.

Nonaka, I., and Takeuchi, H. 1995. "The knowledge-creating company: How Japanese companies create the dynamics of innovation". Oxford Univ. Press, USA.

Nonaka, I.; Toyama, R.; Konno, N. 2000. "SECI, Ba and Leadership: A Unified Model of Dynamic Knowledge Creation”. Long Range Planning, v. 33, n. 1, p. 5-34.

Pasquire, C.; Court, P. 2013. "An exploration of knowledge and understanding - The eighth flow". 21st Annual Conference of the International Group for Lean Construction 2013, IGLC 2013, p. 944-953, 2013.

Polanyi, M. 1966. The Tacit Dimension. UK: Routledge and Kegan.

Koskela, L. 2000. "An exploration towards a production theory and its application to construction". PhD Thesis, University of Technology, Espoo, Finland.

Senge, P.M., and Scharmer, C.O. 2006. "Community action research: Learning as a community of practitioners, consultants and researchers." Handbook of Action Research: Concise Paperback Edition, 195-206.

Skinnarland, S.; Yndesdal, S. 2014. "Barriers to a Continuous Learning". Proc. 22th Ann. Conf. of the Int'l. Group for Lean Construction. Group for Lean Construction, p. 1191-1201. 
Skinnarland, S.; Yndesdal, S. 2012. "The last planner system as a driver for knowledge creation". IGLC 2012 - 20th Conference of the International Group for Lean Construction.

Tyagi, S. et al. 2015. "Lean tools and methods to support efficient knowledge creation". International Journal of Information Management, v. 35, n. 2, p. 204-214.

Zhang, L.; Chen, X. 2016. "Role of Lean Tools in Supporting Knowledge Creation and Performance in Lean Construction”. Procedia Engineering, v. 145, p. 1267-1274. 